\title{
A PROPOSTA DE FORMAÇÃO DAS ESCOLAS ESTADUAIS DE EDUCAÇÃO PROFISSIONAL NO CEARÁ: UMA ANÁLISE À LUZ DA ESCOLA UNITÁRIA GRAMSCIANA
}

\section{THE PROPOSAL OF FORMATION OF THE PROFESSIONAL EDUCATION STATE SCHOOLS IN CEARÁ: AN ANALYSIS BASED ON THE GRAMSCIAN UNITARY SCHOOL}

\author{
Daniele Luciano Marques ${ }^{1}$
}

Antônia de Abreu Sousa ${ }^{2}$

\section{RESUMO}

O artigo tece reflexões sobre a proposta de educação profissional das escolas estaduais do Ceará. Vale enfatizar que essa modalidade de educação atende ao decreto 5.154/2004 que reforça a integração da Educação Profissional ao nível médio, bem como à Lei 11.741/2008 que sugere a integração da Educação Profissional aos diferentes níveis e modalidades de educação e às dimensões do trabalho, das ciências e da tecnologia. Nessa oportunidade, analisamos a escola unitária gramsciana que propõe um tipo de educação para além do imediatismo do mercado laboral. Nesse caminhar, aliamos ao estudo do desenho da educação profissional Brasileira focando as mudanças no mundo laboral, a partir da década de 1970, sobretudo sob a influência da Teoria do Capital Humano e pedagogia produtivista. Para estas apreciações recorremos a Cunha (2000) e Saviani (2008) que discutem os caminhos da Educação Profissional Brasileira. No que se refere às mudanças no mundo do trabalho, utiliza-se contribuições de Frigotto (2010;1995), dentre outros. Vale enfatizar que a pesquisa está ancorada na concepção de escola unitária de Gramsci (1989) ao propor a união entre escola do trabalho manual e escola do trabalho intelectual formando especialistas-dirigentes capaz de unir teoria e prática, em qualquer âmbito laboral, para além das especializações.

Palavras-chave: Educação Profissional- Mundo do Trabalho - Escola Unitária.

\section{ABSTRACT}

The article reflects on the proposal of education of the state schools in Ceará. It is worth emphasizing that this type of education meets the Decree 5.154 / 2004 which reinforces the integration of Vocational Education to the secondary school level, and the Law 11,741 / 2008 suggesting the integration of Vocational Education at different levels and modalities of education and at working , scientifical and technological dimensions. At that time, we analyzed the Gramscian unitary school that offers an education beyond the immediacy of the labor market. This way, we combine the study of the design of the Brazilian 
vocational education focusing on the changes in the working environment, from the 1970s, especially under the influence of the Human Capital Theory and productive pedagogy. For those analyses we use Cunha (2000) and Saviani (2008) who discuss the ways of Brazilian Vocational Education. With regard to changes in the working area, it is used contributions from Frigotto (2010; 1995), among others. It is worth emphasizing that the research is anchored in the Gramsci's unitary school (1989) when it proposes the link between the school of manual labor and the school of intellectual work forming specialists-managers able to unite theory and practice in any field of employment, beyond specializations.

Keywords: Vocational Educational; Working area; Unitary school.

\section{INTRODUÇÃO}

O estudo traz como cerne a educação profissional da rede estadual do Ceará, especificamente integrada ao ensino médio, na perspectiva das transformações no mundo laboral sob a influência da Teoria do Capital Humano. Vale ressaltar que a análise está embasada, principalmente, na concepção de escola unitária do Filósofo Italiano Antônio Gramsci, ao pensar na união entre escola do trabalho manual e escola do trabalho intelectual formando para além do imediatismo do "mercado" laboral.

Ao refletirmos sobre as políticas para a educação profissional que se fortaleceu no país, influenciada pelo ideário de crescimento econômico que associaram a esse tipo de modalidade, entendemos ser oportuno investigar a proposta de educação profissional ofertada pelas escolas estaduais do Ceará, já que tem sido divulgada pela mídia e governo do Estado como uma excelente oportunidade para os jovens que iniciam na caminhada pelo mundo do trabalho. Entretanto, partimos do pressuposto que essa oferta, tal como algumas políticas que se desenharam no contorno educacional brasileiro, propõem um modelo de ensino para manter o status quo da autovalorização do capital e de acriticidade e conformação do trabalhador frente às condições de exploração em sua seara laboral.

Temos que, historicamente, desde o período colonial, a educação profissional brasileira vive uma dualidade e fragmentação que se expressa na educação dividida em classes: ensino do tipo intelectual destinada à elite e 
outro tipicamente manual para os explorados. Assim, o ensino profissional que se instaurou no país, constituiu-se como um meio para adquirir mão de obra, e assim, atender aos interesses da classe hegemônica, estando distante contemplar o desenvolvimento do potencial intelectual do individuo.

Diante da reestruturação produtiva, a partir dos anos de 1970 são evidentes as modificações no âmbito das relações produtivas e o uso da educação como um produto mercadológico. Nesse sentido, sob a égide da Teoria do Capital Humano, não correlata ao desenvolvimento do individuo, a concepção de pedagogia produtivista subordina-se aos ditames da economia. $\mathrm{Na}$ concepção gramsciana, a burguesia tem adotado um modelo educacional que produz e reproduz ideologicamente as diferenças sociais.

A implantação de escolas de educação profissional na rede estadual de ensino enfatiza um relevante momento da política educacional do Ceará. Esse desafio trabalha com a diversificação da oferta de ensino médio articulando com o mundo do trabalho.

Vale lembrar que a educação profissional tem se destacado como um ponto chave para esse novo paradigma técnico e econômico. Levando em consideração o projeto das Escolas Estaduais de Educação Profissional no Ceará, segundo dados fornecidos pela Secretaria dessas escolas, há uma demanda interessante na procura por essa modalidade integrada ao Ensino Médio, uma vez que no ano inicial do projeto as matrículas estavam em número de 4.181. Já em 2013 foram matriculados 36.093, e em 2014 um total de 40.663 .

Desde então, a crescente oferta da modalidade de Educação Profissional integrada ao ensino médio vêm sendo inserida em nosso estado com o intuito de lançar os estudantes em um mundo do trabalho de cunho instável e exigente, pois como afirma Andrade (2010, p.47) "A produção em massa e o cronômetro perdem espaço para a produção flexível", com o intuito de alcançar melhores números e qualidade na produtividade. As atuais estratégias de produção e organização clamam por trabalhadores com uma visão generalista no tocante ao conhecimento, uma vez que esses, além de suas atividades rotineiras, passam a lidar com variações e imprevisões no campo do trabalho. 


\section{A TEORIA DO CAPITAL HUMANO E REESTRUTURAÇÃO PRODUTIVA DELINEANDO A FORMAÇÃO DO TRABALHADOR}

A Teoria do Capital Humano, no contexto mundial, surge pós-guerra fria moldando a educação e resgatando o principio do individualismo. Na seara educacional brasileira, o messianismo ${ }^{3}$ pedagógico atribuído a essa ideologia chega ao Brasil sob o clima da era militar, por volta dos anos 60-70, sendo a grande prova que o capitalismo iria trazer benefícios para todos. No entanto, esse desenvolvimento na educação não correspondeu à melhoria da maioria.

Interessante a alerta de Rossi (1977) e Arapiraca (1979), críticos brasileiros da Teoria do Capital Humano, para esses autores a aquisição de habilidades via educação divulgada por essa teoria não tem sentido de promover o desenvolvimento integral do cidadão. Na verdade, tal teoria induz ao individuo a busca pela ascensão de classe, ao mesmo tempo é contraditória, pois ideologicamente anula e aliena politicamente o individuo. Além disso, "a perspectiva da ascensão social é dissimulada sempre como uma esperança futura, e que é alimentada pela exploração da refinação do consumo supérfluo" implicando em uma maior divisão social laboral e na deterioração das relações sociais. (Arapiraca, 1979, p.43).

$\mathrm{Na}$ acepção de Rossi (1977), equalizar as oportunidades é um forte discurso da ideologia capitalista, já que esse sistema divulga estar disponibilizando os meios para tal fim. Nesse fazer, repassa para o individuo a responsabilidade de seu sucesso ou não.

A educação tornaria permeáveis as classes sociais de modo que quem não 'subisse' ou não teria se esforçado suficiente, ou teria sido menos capaz. Porque a própria existência do 'sistema de liberdade' (capitalismo), tendo acabado com os privilégios de sangue e nobreza é garantia suficiente para eliminação de barreiras à mobilidade social (p.75).

Vale enfatizar que, ideologicamente, a Teoria do Capital Humano utiliza a educação como um meio de proporcionar o desenvolvimento econômico do país. Em vista desse metabolismo instável, o sistema provoca mudanças nos variados aspectos da vida social, sobretudo no trabalho. 
Assim, diante a crise do capitalismo e, consequentemente, a reestruturação produtiva, a partir de 1970, são evidentes as transformações no âmbito do trabalho e no uso da educação como um produto mercadológico. À luz da Teoria do Capital Humano, a concepção de pedagogia produtivista, correlata ao tecnicismo, traz à educação brasileira, na década de 1970, uma orientação subordinada aos ditames da economia. Visto que essa concepção emprega, inculcando a ideologia dominante, o papel da educação para atender às leis do mercado sob a falácia de desenvolvimento econômico.

Compreendemos que esse feito é mantido pelo sistema do capital para controlar a educação e moldar o futuro trabalhador. Nesse sentido, é secundária a posição do discente e do docente, que devem executar o processo de ensino.

Portanto, no âmbito da formação educacional, o escopo da pedagogia produtivista é formar o indivíduo para o "mercado" de trabalho, enfatizando as competências numa formação acrítica. Não há valorização do discente, nem do docente, todavia do capital. Por essa lógica, acredita Saviani (2008), acentua-se "o caos no campo educativo, gerando tal nível de descontinuidade, de heterogeneidade e de fragmentação que praticamente inviabiliza o trabalho pedagógico" (p. 383-384).

A educação nos anos seguintes, ainda inspirada na Teoria do Capital Humano resignificada, passa a ter uma lógica emanada dos interesses privados. Tal modelo de produção substitui o fordismo ${ }^{4}$, que segundo Saviani (2008), opera com trabalhadores polivalentes e despecializados com intuito de obter produtos diversos, em estoque reduzido e assim, atender às demandas especificas do "mercado" cada vez mais exigente.

Para continuar se reproduzindo, o capital necessita de mão de obra qualificada, porém tal formação é limitada e truncada, pois torna, muitas vezes, o trabalhador incapaz de compreender e refletir a posição de explorado que se encontra.

Nessa reestruturação econômica, segundo Frigotto (1995), a "integração, a qualidade e a flexibilidade" são categorias chaves para acionar a produtividade e competitividade almejada. Entretanto, ao tratar a função da educação determinada pela produção econômica, Frigotto (2010) alerta para o 
fato de que o ensino está intimamente definido pelos critérios mercadológicos, longe da acepção política, social, filosófica e ética. Assim, o ato educativo reduz-se a uma tecnologia educacional. Nesse âmbito, a escola não é capaz de elevar cultural e profissionalmente o indivíduo.

Como menciona Saviani (2008), no quesito profissional, o sujeito é que deverá buscar os meios que o torne competitivo.

E o que ele pode esperar das oportunidades escolares já não é o acesso ao emprego, mas apenas a conquista do status de empregabilidade. A educação passa a ser entendida como um investimento em capital humano individual que habilita as pessoas para a competição pelos empregos disponíveis. $O$ acesso a diferentes graus de escolaridades amplia as condições de empregabilidade do individuo, o que, entretanto, não lhe garante emprego, pelo simples fato de que, na forma atual do desenvolvimento capitalista, não há emprego para todos [...] (p. 430).

Nesse sentido, fica evidente o quadro atual denominado de "pedagogia da exclusão", como declara Saviani (2008), uma vez que responsabiliza o sujeito-educando por sua inclusão ou não no campo trabalhista. Essa "conquista" dependerá dele. Além disso, mesmo inserido no mundo do trabalho, atuará sob condições subalternas, seja na informalidade ou não, terceirização, assalariamento, porque estará orientado pelas demandas do capital vigente. Kuenzer (2005, p.91-94 apud Saviani, 2008, p. 442), denomina dialeticamente o atual quadro por 'exclusão includente', referindo-se ao mercado de trabalho e 'inclusão excludente' em se tratando do terreno educativo.

Entendemos que a formação para o trabalho, longe de ser uma conquista, está diretamente e historicamente ancorada na tentativa de formar para o mercado laboral. $\mathrm{Na}$ sociabilidade do Capital torna-se distante a integralidade do trabalhador, o que resta é uma educação determinada pelo sistema de produção, jamais determinante. 


\section{A DUALIDADE NO ENSINO MÉdIO E EDUCAÇÃO PROFISSIONAL NO BRASIL}

A educação instaurada no período de colonização era um importante mecanismo de aculturação, uma vez que as tradições e os costumes que se tentou inculcar decorreram de um dinamismo externo, isto é, do meio cultural do colonizador.

Os primeiros aprendizes de ofício eram incumbidos de servir a colônia, ficando clara a dualidade da educação brasileira: ensino do tipo intelectual destinada à elite e outro do tipo servidão para os explorados.

O ensino profissional que se delineou no país, no período colonial, constituiu-se como uma ferramenta para adquirir mão de obra, e assim, atender aos interesses das classes dominantes.

\footnotetext{
Nesse período, dos ofícios da colonização, já começava a delinear-se o que seria a tendência dominante na educação brasileira: o ensino e a prática de ofícios manuais era destinado aos índios e órfãos, ou seja, aos estratos subordinados da sociedade, e o ensino de humanidades, dirigido aos filhos de proprietários, visando à formação de uma elite dirigente segundo os padrões de ensino da metrópole (BRYAN, 2008, p. 12)
}

As primeiras iniciativas de lançar no Brasil, oficialmente, o ensino profissional foram orientadas com intenção assistencial, pois eram destinadas a "amparar os órfãos e os demais desvalidos da sorte", conforme nos revela Regattieri e Castro (2009, p.19). De acordo com os autores supracitados, a primeira iniciativa, "criação do Colégio das Fábricas, pelo Príncipe Regente D. João, em 1809, no entanto, já estava relacionada às necessidades emergentes da economia [...]" (p.19). Além disso, dentre as associações civis criadas, temos os Liceus de Artes e Ofícios, cujo objetivo era ajudar crianças órfãs e desamparadas, assim eram instruídas para iniciar ocupações industriais.

Com a chegada da República, a educação profissional mantém ainda o caráter assistencial, sendo que com o processo de industrialização e chegada do capitalismo, a sociedade brasileira passa a exigir um tipo de trabalhador mais "capacitado", uma vez que o processo de produção, os avanços das técnicas e da ciência passam por profundas transformações. 
Para Regattieri e Castro (2009), no início do século XX é dado um pontapé nas políticas referentes à educação profissional, já que em 1910, em vários estados, foram implantadas 19 Escolas de Aprendizes Artífices "destinadas 'aos pobres e humildes', vindo a se constituírem no embrião da atual rede de instituições federais de educação tecnológica" (p.19). No entanto, é evidente que tal política atende aos valores capitalistas.

No período ditatorial do Governo de Getúlio Vargas, foi promulgada a Constituição de 1937. Nessa legislação, o ensino profissional é "contemplado", sob o discurso de atender as classes menos favorecidas, conforme artigo 129, (BRASIL, 1937):

O ensino pré-vocacional profissional destinado às classes menos favorecidas é em matéria de educação o primeiro dever de Estado. Cumpre-lhe dar execução a esse dever, fundando institutos de ensino profissional e subsidiando os de iniciativa dos Estados, dos Municípios e dos indivíduos ou associações particulares e profissionais.

A referida constituição enfatiza a contribuição das indústrias e dos sindicatos. Tal posição foi influenciada pelos princípios tayloristas/fordistas que se difundiram no Brasil e pressionada pelos dirigentes do país. A educação profissional, portanto, passa a ter o escopo de lançar no mercado de trabalho mão de obra para atender ao processo de industrialização, embora não dispensando a tradição assistencialista.

A educação profissional tornou-se obrigatória nos meados dos anos 70. Na Lei de Diretrizes e Bases (LDB) 5.692/1971, há a pretensão de eliminar o dualismo existente entre escola de $2^{\circ}$ grau normal e escola profissionalizante. Desse modo, a escola passa a ser única, de formação geral e em seguida para o trabalho. Sendo assim, o ensino de $1^{\circ}$ grau estava voltado para "educação geral" e o ensino de $2^{\circ}$ grau para "formação especial" (BRASIL, 1971).

Segundo Cunha (2000, p.15),

A implantação da Lei n. 5692/71 foi cheia de peripécias, desde os floreios ilustrados dos membros do Conselho Federal de Educação, que discorriam sobre o mundo do trabalho com uma desenvoltura desconcertante, até os disfarces das escolas das redes públicas e privadas para fazerem crer que ofereciam ensino profissionalizante para formar técnicos e auxiliares técnicos. 
Anos depois, a educação profissional esteve impedida de integrar-se ao ensino médio, com o Decreto 2.208/1997, do então presidente Fernando Henrique Cardoso, que separou formalmente o ensino técnico da formação geral e básica. O modelo de organização curricular inserido no Decreto 2.208/1997 impossibilitou a oferta do ensino médio integrado ao técnico (BRASIL, 1997).

A desintegração do ensino profissional ao ensino médio "somente se reverteu com os esforços da sociedade civil, sobretudo das entidades científicas e sindicais" (OLIVEIRA, 2004).

Sob o amparo do Decreto 5.154/2004, do Governo Lula, o Ensino Médio pôde ser ofertado integrado à Educação Profissional, de modo que a articulação entre a educação profissional técnica de nível médio e o ensino médio dar-se-ia de forma: integrada ou concomitante (BRASIL, 2004).

Com o decreto 5.154/2004, embora o Ensino Médio possa ser ofertado integrado à Educação Profissional, precisamos estar atentos em relação às verdadeiras intenções e caminhos que tem tomado a formação dos trabalhadores, uma vez que parece dar continuidade a íntima relação entre educação profissional e exigências dos setores produtivos.

Dando prosseguimento às políticas na Educação Profissional, ainda no governo citado, surge o Decreto № 6.302, em 12 dezembro de 2007 que instituiu o Programa Brasil Profissionalizado. Segundo Art. 1ํ:

\footnotetext{
Fica instituído, no âmbito do Ministério da Educação, o Programa Brasil Profissionalizado, com vistas a estimular o ensino médio integrado à educação profissional, enfatizando a educação científica e humanística, por meio da articulação entre formação geral e educação profissional no contexto dos arranjos produtivos e das vocações locais e regionais. (BRASIL, 2007)
}

Entre os objetivos desse programa está a proposta de ampliar e reestruturar o ensino médio, englobando "formação geral, científica e cultural com a formação profissional dos educandos", além de promover a elevação da oferta de matrículas no ensino médio integrado à educação profissional, pela rede pública de educação dos Estados, do Distrito Federal e dos Municípios. Contudo, esperamos que as propostas descritas no decreto supracitado não sejam apenas meios de elevar os números estatísticos educacionais. 


\section{A PROPOSTA DAS ESCOLAS ESTADUAIS DE EDUCAÇÃO PROFISSIONAL NO CEARÁ: FORMAÇÃO PARA O TRABALHO OU PARA O MERCADO?}

O Governo do Estado do Ceará, em parceria com o governo federal e atendendo ao decreto $n^{0}$ 6.302/2007 que instituiu o Programa Brasil Profissionalizado, aprovou a lei no 14.273/2008 que Dispõe sobre a criação das Escolas Estaduais de Educação Profissional - EEEP, sob a Coordenação da Secretaria de Educação do Ceará. Em todo Ceará, no ano de 2014, somamos 106 escolas em funcionamento.

A política pública de Educação Profissional ao qual se refere o estudo caracteriza-se como uma "estratégia" para efetivar uma conhecida necessidade e aspiração dos jovens, englobando a educação escolar, o trabalho e as práticas sociais, conforme declara o governo estadual.

À nível nacional, a Educação Profissional da rede estadual, apresentou sequencialmente aumento no número de matrículas durante os anos de 2007 a 2012. Nesse último ano, foram matriculados 448.543 estudantes. Comparado a 2007, houve um aumento de aproximadamente 56\% no quantitativo de alunos (BRASIL, 2013). Os dados são do Censo Escolar da Educação Básica.

Em relação à expansão do número de escolas profissionais em nossa capital, temos que no ano inicial do projeto, em 2008, havia seis escolas. Os cursos ofertados, inicialmente, eram: Técnico em Informática, Técnico em Enfermagem, Guia de Turismo, Técnico em Segurança do Trabalho. Em 2007, duplicou o número de instituições ofertando esse tipo de educação. Já em 2010, Fortaleza estava com 17 escolas profissionais funcionando, permanecendo com esse quantitativo em 2012. No ano de 2013, tivemos 18 escolas. Atualmente, são 19 em funcionamento.

Quanto aos cursos, passados seis anos, já foram ofertados mais de 51 tipos nessa modalidade, distribuídos nos eixos tecnológicos: ambiente e saúde; controle e processos industriais; desenvolvimento educacional e social; gestão e negócios; informação e comunicação; infraestrutura; produção 
alimentícia; produção cultural e design; produção industrial; recursos naturais; segurança; turismo, hospitalidade e lazer.

Além das instituições que estão sob a responsabilidade da Superintendência das Escolas Estaduais de Fortaleza - SEFOR, os prédios estão distribuídos entre as 20 Coordenadorias Regionais de Desenvolvimento da Educação - CREDES.

Dados da Coordenadoria das Escolas Estaduais de Educação Profissional do Ceará revelam que em todo estado foram matriculados, nessa modalidade de ensino, 4.181 alunos em 2008 e 40.663 em 2014, correspondendo um aumento de quase $1000 \%$ entre o inicio da oferta até o último ano contabilizado.

Nessa formação "integral" há uma divisão de atividades, já que no período da manhã, o aluno se dedica à conclusão do Ensino Médio, e no período vespertino, trata-se da área especifica do curso técnico. Os cursos são desenvolvidos em três anos, sendo dois anos e meio em tempo integral, além do estágio supervisionado que acontece no contraturno quando o estudante chega ao 6ำ semestre. O Projeto Pedagógico alia a formação geral, científica e cultural com a formação profissional e cidadã dos discentes. Essas escolas funcionam em tempo integral, ou seja, em dois turnos, das 07 horas às 17 horas, de segunda a sexta-feira. No período da manhã, o aluno se dedica a conclusão do Ensino Médio, já no período da tarde, ele faz um curso técnico na própria escola. Em relação à Matriz Curricular do Curso Técnico em Nível Médio de Informática (ANEXO C), a carga horária totaliza 5400 horas/aulas que se dividem em componentes da Formação Geral, Formação Profissional e Parte Diversificada. (CEARÁ, SEDUC, 2013)

De acordo com a Secretaria de Educação do Estado do Ceará, a missão da Educação profissional de nível médio técnico é de que haja uma integração ampla da formação e vivência de cidadania e de protagonismo juvenil.

No que concerne à filosofia de gestão dessa política pública, esta baseia-se na Tecnologia Empresarial Socioeducacional (TESE) do Programa de Desenvolvimento dos Centros de Ensino Experimental - PROCENTRO de Pernambuco via parceria com o Instituto de Co-responsabilidade pela 
Educação - ICE desse estado (Magalhães, 2013). É importante frisar que a TESE é uma filosofia de gestão inspirada na Tecnologia Empresarial Odebrecht (TEO), composta por princípios, conceitos e critérios desenvolvidos pelo fundador da Organização. A TESE tem sido a referência para a implantação da Educação Profissional da Rede Estadual Cearense. Essa diretriz passou a fazer parte dos treinamentos de formação dos Gestores, uma vez que as instituições de Ensino em tempo integral norteiam-se nos padrões gerenciais à luz da experiência empresarial.

No Manual Operacional da TESE em que trata de uma nova escola para a juventude brasileira (Escola de Ensino Médio em Tempo Integral), o presidente do ICE apresenta o lema e sua concepção sobre a TESE alegando que a referida tecnologia pode reverter a situação da educação pública brasileira .

'Quem não planeja não executa; quem não mede não sabe de nada.' A TESE (Tecnologia Empresarial Socioeducacional) foi desenhada para levar esses conceitos gerenciais para o ambiente escolar e permitir ao Gestor o atingimento dos seus objetivos de maneira estruturada e previsível. Eu considero esta metodologia a espinha dorsal do processo de transformação da escola pública brasileira, tão mal planejada, tão mal gerida e que produz, como consequência, resultados tão pífios (MAGALHÃES, 2013, p. 4).

De acordo com o histórico da Odebrecht, esta foi fundada na Bahia, em 1944, por um engenheiro pernambucano, cujo nome intitulou o empreendimento: Norberto Odebrecht Construtora S.A. Sendo esse o marco fundador da Organização Odebrecht. Atualmente, essa está agrupada em empresas de negócios, investimentos e instituições auxiliares que compõem a estrutura da Organização. Dentre as parcerias com empresas brasileiras e internacionais, temos: Banco do Nordeste, OI, Sebrae, Semp Toshiba, DELL, Michelin e Microsoft (ODEBRECHT, 2013),.

Vale ressaltar que na página inicial da Fundação Odebrecht é enfatizado que

A TEO assegura a unidade de pensamento e ação das Pessoas nos diferentes negócios, países e contextos culturais em que atuam. Assim, é possível atender às necessidades dos Clientes, agregar valor ao patrimônio dos Acionistas, reinvestir os resultados 
alcançados e crescer em frentes distintas (ODEBRECHT, 2013, grifos nossos).

Em relação ao modelo de Escolas Estaduais de Educação Profissional, a TESE orienta o projeto para elaboração anual de um Plano de Ação que dentre os princípios básicos estão, a saber: Protagonismo Juvenil: Formação Continuada, Atitude empresarial, Corresponsabilidade e Replicabilidade. De acordo com o Manual Operacional da TESE, cada premissa sofre variação levando em conta "a realidade local, nível de entendimento e experiências vivenciadas" (MAGALHÃES, 2013, p.21).

Compete citar que o quadro gerencial da educação pública pós anos 90, influenciado pelos ditames da Teoria do Capital Humano, passou por mudanças que a aproximaram do modelo de gestão das empresas privadas. Em vista disso, pensamos que esse desenho tenha influenciado o governo cearense a seguir os preceitos da TESE.

Não podemos esquecer de que Gramsci (1989) alertava-nos para o tipo de escola que era destinava à classe trabalhadora, conforme veremos no tópico a seguir. Temos nas políticas neoliberais e no falar do governo estadual em questão, que a oferta nas EEEP's é a melhor alternativa para a educação do trabalhador.

Finalizando esse tópico compreendemos que a Educação profissional "integrada" a nível médio é um desafio, uma vez que envolvem as complexas questões do mundo do trabalho. Nessa perspectiva, não basta inserir os alunos nas escolas é preciso certificar a proposta e as relações dessa formação conquistada, uma vez que a filosofia que a orienta aponta para uma estreita relação com interesses do capital.

\section{A PROPOSTA DE ESCOLA UNITÁRIA GRAMSCIANA: FORMANDO PARA ALÉM DAS ESPECIALIZAÇÕES}

O filosofo e ativista politico italiano Antônio Gramsci trouxe relevantes contribuições para a discussão na luta social pela transformação da sociedade capitalista no século XX. A teoria gramsciana repensa as contradições do funcionamento da sociedade capitalista expressadas pelo marxismo. Gramsci traz o conceito de superestrutura como 
espaços/instituições que legitimam a circulação de ideologias que nutrem as relações de classe via dominação hegemônica política/estatal e sociedade civil. Para Gramsci (1989), o papel da sociedade civil seria mesmo de perpetuar as relações de classe e prevenir a própria consciência da classe. Assim, acabam produzindo e reproduzindo a hegemonia.

Para superação da dominação torna-se imperioso, na concepção de Gramsci, uma contra-hegemonia oriunda da organização da classe trabalhadora com finalidade de chegar a uma nova moral e nova cultura, além de combater a dicotomia ideológica difundida pela burguesia.

Segundo Manacorda (1990), Gramsci não propõe uma educação para o trabalho, mas um trabalho como principio educativo. A "escola unitária" idealizada por Gramsci, crítica à escola soviética e Reforma Gentile ${ }^{5}$, contempla "todas as gerações, sem divisões de grupos ou castas" GRAMSCI, 1989, p.121). Além disso, para essa concepção o ensino deve ser público e para todos, com novas relações entre o "trabalho intelectual" e o "trabalho industrial" para além do chão educacional (p.125).

Ao analisar o Caderno 12 de Gramsci escrito durante o cárcere do filosofo italiano no período facista, Nosella (1992) expõe a estrutura da escola unitária desinteressada ${ }^{6}$. Inicialmente um ensino de noções 'instrumentais' da instrução vinculada a elementos do Estado e sociedade, como forma de conceber o mundo e superar as concepções míticas. "O caráter didáticodiretivo será abandonado à medida que o jovem supera e vence a fase 'instintiva', tornando-se, ao assumir e internalizar os mecanismos e as leis da sociedade, um homem livre, autônomo e criativo" (p. 116). Na fase final da escola, atual ensino médio, o jovem estuda em uma estrutura ativa, participativa e criativa. Somente após essa fase última, chega-se ao ensino profissional, por meio da universidade/academia, sendo concreta a dimensão prática para o exercício contíguo e consciente das profissões.

$\mathrm{Na}$ perspectiva gramsciana, a burguesia tem adotado um modelo educacional que produz e reproduz ideologicamente as diferenças sociais. Conforme Mochcovitch (1988), Gramsci ao refletir sobre a escola profissionalizante acredita que essa "é uma forma imediatista de sujeitar a socialização das crianças e dos jovens, a formação dos homens, à lógica da 
produção, e, portanto à lógica do capitalismo [...]" (p.55). Pensando na escola profissional atual, essa é vista como democrática, e ao permitir uma qualificação ao trabalhador, cria uma falsa mobilidade social. Assim,

[...] graças à crise profunda da tradição cultural e da concepção da vida e do homem, verifica-se um processo de progressiva degenerescência: as escolas de tipo profissional, isto é, preocupadas em satisfazer interesses práticos imediatos, tomam a frente da escola formativa, imediatamente desinteressada. $\mathrm{O}$ aspecto mais paradoxal reside em que este novo tipo de escola aparece e é louvada como democrática, quando na realidade, não só é destinada a perpetuar as diferenças sociais, como ainda a cristalizá-las em formas chinesas. (GRAMSCI, 1989, p.136).

Enfim, a escola unitária gramsciana tem um olhar na perspectiva de emancipação humana a partir da consciência dos cidadãos, principalmente, da dominada classe trabalhadora no que se refere à construção de uma concepção de mundo e de uma formação política.

No contexto italiano do século XX, o filosofo Antônio Gramsci criticava a divisão da escola em clássica e profissional, já que a escola profissional tinha o papel de formar mão-de-obra, pois era destinada às classes de afazeres instrumentais; ao passo que a escola clássica recebia a classe dominante e os intelectuais.

Vale enfatizar que essa disposição cravou raízes que se estabelecem até os dias atuais. Assim, Gramsci, ao falar sobre a crise da sociedade da época, declarou que o "fato de que um tal clima e um tal modo de vida tenham entrado em agonia e que a escola se tenha separado da vida determinou a crise da escola". Gramsci (1989) afirmava que a tendência

[...], é a de abolir qualquer tipo de escola 'desinteressada' (não imediatamente interessada) e 'formativa', ou conservar delas tãosomente um reduzido exemplar destinado a uma pequena elite de senhores e de mulheres que não devem pensar em se preparar para um futuro profissional, bem como a de difundir cada vez mais as escolas profissionais especializadas, nas quais o destino do aluno e sua futura atividade são predeterminados (p.118).

Notamos nessas palavras a preocupação do teórico em propor uma saída para o colapso pela qual passava a função da escola. Assim, Gramsci 
pensava em uma escola "humanista" que, desde a infância até o momento da escolha profissional tivesse caráter desinteressado.

Nesse fazer, Gramsci traz a ideia de escola unitária para reverter a crise do sistema educativo italiano. Esse filósofo tinha consciência de que a escola unitária significaria "o inicio de novas relações entre o trabalho intelectual e trabalho industrial" (p.125) não apenas na seara do chão escolar, sobretudo em toda vida social.

Concordando com a concepção gramsciana, uma formação polivalente, desinteressada e culturalmente transformadora seria a forma apropriada de preparar o aluno para a vida e para o trabalho em qualquer esfera que escolher.

Um ponto importante, no estudo da organização prática da escola unitária, é o que diz respeito à carreira escolar em seus vários níveis, de acordo com a idade e com o desenvolvimento intelectual-moral dos alunos e com os fins que a própria escola pretende alcançar. A escola unitária ou de formação humanista (entendido este termo, 'humanismo', em sentido amplo e não apenas no sentido tradicional) ou de cultura geral deveria se propor à tarefa de inserir os jovens na atividade social, depois de tê-los levado a um certo grau de maturidade e capacidade, à criação intelectual e prática e uma certa autonomia na orientação e na iniciativa." (Gramsci, 1989, p.121)

Esse tipo de escola funcionaria a partir da organização dos prédios, materiais, livros e corpo docente. Interessante a preocupação de Gramsci (1989) com a questão ensino-aprendizagem. Para esse pensador, faz-se necessário a ampliação do quadro docente, "pois a eficiência da escola é muito maior e intensa quando a relação entre professor e aluno é menor" (p.121).

O primeiro grau elementar não deveria ultrapassar três-quatro anos e, ao lado do ensino das primeiras noções "instrumentais" da instrução (ler, escrever, fazer contas, geografia, história), deveria desenvolver notadamente a parte relativa aos 'direitos e deveres', atualmente negligenciada, isto é, as primeiras noções do Estado e da sociedade, como elementos primordiais de uma nova concepção do mundo que entra em luta contra as concepções determinadas pelos diversos ambientes sociais tradicionais, ou seja, contras as concepções que poderíamos chamar de folclóricas. (1989, p.122)

Gramsci deixa claro que a questão dogmática precisa existir como forma de orientação nesses anos iniciais, mas necessita ser moldada. $O$ 
restante do curso poderia ter duração não mais do que seis anos para que a conclusão de toda escola unitária pudesse culminar em torno dos quinze ou dezesseis anos.

Neste sentido, Gramsci pensa a educação humana mesmo na fase pré-escolar, pois para ele é relevante a existência de uma rede de auxílios à infância para que as crianças se habituem mais rapidamente à carreira escolar. O referido pensador acreditava que a escola unitária deveria ser um espaço de aprendizagem criadora e coletiva.

De fato, a escola unitária deveria ser organizada como colégio, com vida coletiva diurna e noturna, liberta das atuais formas de disciplina hipócrita e mecânica, e o estudo deveria ser feito coletivamente, com a assistência dos professores e dos melhores alunos, mesmo nas horas de aplicação chamada individual, etc.(1989, p. 123).

Gramsci detecta um grande entrave na organização escolar, pois não entendia o fato de que a escola média disponível nada se diferenciava do ensino proporcionado nos anos anteriores, já que a única diferença que se apresentava era uma "abstrata suposição de uma maior maturidade intelectual e moral do aluno" (1989, p. 123, grifos nossos), que para ele ocorria apenas pela maioridade que se atinge e pela acumulação de experiência da fase anterior. Portanto, não existiam ganhos qualitativos (amadurecimento crítico) nessa passagem de escola inicial para a escola média.

Nesse contexto, para Gramsci (1989) a última fase da escola unitária é decisiva e orientacional, pois "se tende a criar os valores fundamentais do 'humanismo', a autodisciplina intelectual e a autonomia moral necessárias a uma posterior especialização" (p.124) que se direcionam para os estudos na universidade (científico) ou para atividades de cunho produtivo. Assim, nesta fase final da escola unitária está a oportunidade de desenvolver e fortalecer a autonomia dos discentes, daí ser considerada como etapa criadora.

Essa fase que tem base no principio da coletividade "não significa escola de 'inventores e descobridores'; ela indica uma fase e um método de investigação e de conhecimento" (Gramsci, 1989, p. 125), não diz respeito a um receituário que obrigue à inovação de qualquer modo. Para esse estudioso, descobrir uma verdade pelo próprio mérito, sem a mão de outrem, é criação 
"(mesmo que a verdade seja velha) e demonstra a posse do método; indica que, de qualquer modo, entrou-se na fase da maturidade intelectual na qual se pode descobrir verdades novas” (1989, p. 125). Desse modo, Gramsci direciona para que essa fase tenha habitação nas bibliotecas, nos laboratórios, em seminários, enfim, em espaços inspiradores para tal proposito.

Com o olhar dialético, Gramsci (1989) alerta que a educação deve acontecer para além do chão da escola (prédio físico), pois a cultura precisa ser ativa nos diversos ambientes sociais para que de modo natural os conhecimentos sejam desenvolvidos e fortalecidos, possibilitando assim o acesso da limitada classes trabalhadora a esses bens intelectuais que por muitos anos têm estado na posse da classe hegemônica.

Se se quer destruir esta trama, portanto, deve-se evitar a multiplicação e graduação dos tipos de escola profissional, criandose, ao contrário, um tipo único de escola preparatória (elementarmédia) que conduza o jovem até os umbrais da escolha profissional, formando-o, entrementes como pessoa capaz de pensar, de estudar, de dirigir ou de controlar quem dirige (p.136).

Para Gramsci (1989) "não pode consistir apenas em que um operário manual se torne qualificado, mas em que cada 'cidadão' possa se tornar 'governante' e que a sociedade o coloque, ainda que 'abstratatamente', nas condições gerais de poder fazê-lo" (p.137). Com seu caráter revolucionário, o referido filósofo concebia o trabalho como principio educativo, no entanto tecia severas criticas ao modelo de escola profissional italiana que elaboraram para a classe trabalhadora.

\section{CONSIDERAÇÕES FINAIS}

Diante da dualidade e fragmentação educacional que se estabeleceu na relação entre o ensino médio e a educação profissional propagada, historicamente, desde a Colônia, pela sociedade de classes, não podemos nos esquecer de que as propostas de educação profissional no Brasil, não se centraram no aprendiz, todavia estiveram submetidas aos ditames economicistas. 
$\mathrm{Na}$ sociedade capitalista temos uma escola profissional "motivadora" que induz o sujeito à busca por uma qualificação como possibilidade de ascensão de classe. Contudo, trata-se de uma escola ahistórica e apolítica reforçando as desigualdades no campo laboral e consequentemente desequilibrando a vida societal.

É importante citar que Gramsci traz a educação como ideia de elevação cultural. A escola unitária é a escola do trabalho manual e trabalho intelectual que enfatiza a formação para além das especializações, isto é, uma formação de intelectuais especialistas-dirigentes capaz de unir teoria e prática, em qualquer âmbito laboral, distante das propostas que presenciamos ao longo da história da educação brasileira. Contudo, entendemos que a escola unitária de Gramsci, taticamente, torna-se impossível nos moldes capitalistas. Assim, a elevação cultural dos trabalhadores é imprescindível, visto que há uma urgência de que compreendam o mundo, elaborem críticas e participem diretamente do governo da sociedade.

Por fim, somos convidados a perceber que é imperiosa a ampliação de estudos no que se refere ao processo de educação profissional no Brasil, uma vez que a temos como aliada na disputa e luta social. Assim, não basta oferecer essa modalidade, contudo faz-se necessário garantir a formação do trabalhador para além das limitações economicistas do mercado de trabalho.

\section{REFERÊNCIAS}

ANDRADE, Rejane. Mercado de Trabalho e Formação profissional do jovem trabalhador no Estado do Ceará. In. SOUSA, Antônia de Abreu (Org).

Trabalho, Educação e arte: encontro, desencontros e realidade. Fortaleza: Edições UFC, 2010.

ARAPIRACA, J. O. AUSAID e a Educação Brasileira: um estudo a partir de uma abordagem crítica da Teoria do Capital Humano. Rio de Janeiro, 1979. Dissertação. 237p.

BRASIL. Constituição (1937). Constituição da República Federativa do Brasil: de 10 de novembro de 1937. Republicada no DOU, em 19 de novembro de 1937.

Decreto n. 2.208, de 17 de abril de 1997. Regulamenta o $\S 2 \circ$ do art. 36 e os arts. 39 a 42 da Lei n․ 9.394, de 20 de dezembro de 1996, que 
estabelece as diretrizes e bases da educação nacional. Publicado no DOU, em 18 de abril de 1997.

. Decreto n. 5.154, de 23 de julho de 2004. Regulamenta o $\S 2^{\circ}$ do artigo 36 e os arts. 39 a 41 da Lei n. 9.394, de 20 de dezembro de 1996, que estabelece as diretrizes e bases da educação nacional, e dá outras providências. Publicado no DOU, em 26 de julho de 2004.

. Decreto n. 6.095, de 12 de dezembro de 2007. Institui o Programa Brasil Profissionalizado. Publicado no DOU, em 13 de dezembro de 2007.

. Lei n. 5.692, de 11 de agosto de 1971. Fixa Diretrizes e Bases para o ensino de $1^{\circ}$ e $2^{\circ}$ graus, e dá outras providências. Publicado no DOU, em 12 de agosto de 1971.

BRASIL. Instituto Nacional de Estudos e Pesquisas Educacionais Anísio Teixeira. Censo escolar da educação básica: 2012. Resumo Técnico. Brasília - DF, 2013. Disponível em:

<http://download.inep.gov.br/educacao_basica/censo_escolar/resumos_tecnico s/resumo_tecnico_censo_educacao_basica_2012.pdf.> Acesso em 11 julho 2014.

BRYAN, Newton Antonio Paciulli. Educação, processo de trabalho, desenvolvimento econômico: contribuição ao estudo das origens e desenvolvimento da formação profissional no Brasil. Campinas, SP: Alínea, 2008.

CEARÁ. Secretaria de Educação. Ensino Médio Integrado. 2008. Disponível em: <http://www.ceara.gov.br/governo-do-ceara/projetos-estruturantes/ensinomedio-integrado>. Acesso em: 4 dezembro 2013.

CUNHA, Luiz Antônio. O Ensino profissional na irradiação do

industrialismo. São Paulo: Editora UNESP, Brasília, DF: FLACSO, 2000.

FRIGOTTO, Gaudêncio. A produtividade da Escola Improdutiva. 9.ed. São Paulo. Ed. Cortez/Autores Associados, 2010.

. Educação e a Crise do Capitalismo Real. São Paulo. Ed. Cortez/Autores Associados, 1995.

GRAMSCI, Antônio. Os Intelectuais e a Organização da Cultura. Tradução Carlos Nelson Coutinho. 7ª ed. Civilização Brasileira: Rio de Janeiro, 1989.

MAGALHÃES. Marcos A. Manual Operacional, Modelo de Gestão Tecnologia Empresarial Socioeducacional (TESE). Disponível em :< http://pt.scribd.com/doc/243320991/TESE-Manual-Operacional-Modelo-deGestao-pdf>. Acesso em: dezembro de 2013. 
MANACORDA, Mário. A. O princípio educativo em Gramsci. Tradução de William Lagos. Porto Alegre: Artes Médicas, 1990.

MOCHCOVITCH. Luna Galano. Gramsci e a Escola. São Paulo: Ática, 1988.

NOSELLA, Paolo. A Escola de Gramsci. Porto Alegre: Artes Médicas, 1992.

ODEBRECHT. Organização Odebrecht. Disponível em:<

http://www.odebrecht.com/pt-br/organizacao-odebrecht/tecnologia-empresarialodebrecht>. Acesso em: dezembro de 2013.

OLIVEIRA, Elenilce Gomes de. A Reforma e contra-reforma da Educação. Anais do 27aㅗ reunião anual da ANPED. Caxambu, 2004.

REGATTIERI, Marilza M. G.; CASTRO, Jane Margareth (Orgs.). Ensino médio e educação profissional: desafios da integração. Brasília: UNESCO, 2009.

ROSSI, Wagner G. Capitalismo e Educação. São Paulo, 1977. Dissertação. $188 p$.

SAVIANI, Dermeval. História das ideias pedagógicas no Brasil. 2.ed. Campinas- SP: Autores Associados, 2008.

\footnotetext{
${ }^{1}$ Mestranda em Educação Brasileira pela Universidade Federal do Ceará (UFC).

2 Doutora em Educação pela Universidade Federal do Ceará (UFC). Docente do Instituto Federal de Educação, Ciência e Tecnologia do Ceará (IFCE).

${ }^{3}$ O termo messiânico no âmbito da tese de mestrado de Rossi (1977) aparece como referência ao caráter salvador associado à educação, tendo como parâmetro a Teoria do Capital Humano.

${ }^{4}$ Vale ressaltar que o modelo fordista foi construído pela classe trabalhadora - que reivindicaram direitos trabalhista aposentadoria, salário, dentre outros. Não foi concessão direta do capital.

${ }^{5}$ A Reforma Gentile, sob o governo facista, inseriu o ensino católico como modo de "dominío" do povo, além de dar seguimento a desvinculação entre formação intelectual e formação profissional. Essa reforma pretendeu restaurar a escola para constituir um novo homem via controle e autoritarismo.

${ }^{6}$ A escola desinteressada, na escrita de Gramsci, refere-se ao ensino não direcionado à formação de mão-de-obra para atender o mercado. Contudo, uma escola para proporcionar a humanização capaz de desenvolver capacidades para além das especializações. O referido teórico propõe uma educação na perspectiva marxiana, isto é, orientada para formar o homem omnilateral e não o fortalecer a onilateralidade que deprecia o ser.
}

RECEBIDO EM: novembro/2014

APROVADO EM: dezembro/2014 